\title{
Representação e simbolismo: artes visuais na fronteira Brasil/Bolívia
}

\author{
Representation and symbolism: visual arts on the Brazil/Bolivia frontier \\ Representación y simbolismo: artes visuales en la frontera de Brasil/Bolivia \\ Paulo César Antonini de Souza ${ }^{1}$; Derick Trindade Bezerra ${ }^{2}$ \\ Universidade Federal de Mato Grosso do Sul, UFMS, Campo Grande-MS, Brasil
}

\begin{abstract}
RESUMO
Tendo por campo de investigação o Festival da América do Sul Pantanal (FASP) em 2018, na cidade de Corumbá (Brasil), objetiva-se identificar a materialidade e conceitos que permeiam as manifestações artísticas bidimensionais nesta região de fronteira, a partir da percepção de artistas da Bolívia. A pesquisa se organizou em duas fases: na primeira foi realizado um levantamento em plataformas online de produções acadêmicas em artes visuais, com foco no trabalho bidimensional, utilizando os descritores "arte popular" e "estética latina" resultando em três artigos. Na segunda fase foram selecionados dois trabalhos de uma artista da Bolívia, participante da mostra "Conexão Santa Cruz", realizada durante o FASP 2018, que foram analisados em seus níveis representacional e simbólico. Pela interpretação das imagens foi possível construir uma leitura sobre a perspectiva da artista a respeito de suas condições culturais dentro da ordenação social em que se encontra situada.
\end{abstract}

Palavras-chave: Artes Visuais. Arte Popular. Arte Regional. América Latina.

\begin{abstract}
Having as research field the Festival da América do Sul Pantanal (FASP) in 2018, in the city of Corumbá (Brazil), the objective is to identify the materiality and concepts that permeate the two-dimensional artistic manifestations in this border region, from the perception of artists from Bolivia. The research was organized in two phases: in the first, a survey was carried out on online platforms of academic productions in visual arts, focusing on two-dimensional work, using the descriptors "arte popular" and "estética latina" resulting in three articles. In the second phase, two works were selected by an artist from Bolivia, participating in the exhibition "Conexão Santa Cruz", held during FASP 2018, which were analyzed at their representational and symbolic levels. Through the interpretation of the images, it was possible to construct a reading on the artist's perspective regarding her cultural conditions within the social order in which she is located.
\end{abstract}

Keywords: Visual Arts. Folk Art. Regional Art. Latin America.

\section{RESUMEN}

Teniendo como campo de investigación el Festival de Sudamérica Pantanal (FASP) en 2018, en la ciudad de Corumbá (Brasil), el objetivo es identificar la materialidad y conceptos que permean las manifestaciones artísticas bidimensionales en esta región fronteriza, desde la percepción de artistas de Bolivia. La investigación se organizó en dos fases: en la primera, se realizó una encuesta en plataformas online de producciones académicas en artes visuales, con foco en el trabajo bidimensional, utilizando los descriptores "arte popular" y "estética latina" dando como resultado tres artículos. En la segunda fase, dos obras fueron seleccionadas por un artista de Bolivia, participante de la exposición "Conexão Santa Cruz", realizada durante FASP 2018, que fueron analizadas en sus niveles representativos y simbólicos. A través de la interpretación de las imágenes, fue posible construir una lectura sobre la perspectiva de la artista sobre sus condiciones culturales dentro del orden social en el que se ubica.

Palabras clave: Artes Visuales. Arte Popular. Arte Regional. América Latina.

\footnotetext{
${ }^{1}$ Professor Adjunto dos cursos de Artes Visuais da Faculdade de Artes, Letras e Comunicação (FAALC) da UFMS. Coordenador do Programa de Mestrado Profissional em Artes (PROF-ARTES/FAALC) da UFMS. Líder do Grupo de Pesquisa: Núcleo de Investigação de Fenomenologia em Artes (NINFA/UFMS). E-mail: paulo.antonini@ufms.br. ORCID: https://orcid.org/0000-0003-4040-1485.

Licenciado em Artes Visuais pela FAALC/UFMS. Membro do NINFA/UFMS. E-mail: dericktbezerra@gmail.com. ORDIC: https://orcid.org/0000-0002-9803-5679.
} 


\section{INTRODUÇÃO}

A presente investigação, resultado de Pesquisa de Iniciação Científica desenvolvida durante o biênio 2018-2019 na Faculdade de Artes, Letras e Comunicação da Universidade Federal de Mato Grosso do Sul, se volta para as criações de artistas populares de origem latino-americana, por meio de uma aproximação com poéticas nas linguagens bidimensionais (desenho, pintura, gravura), objetivando reconhecer e ordenar elementos simbólicos dos processos criativos nas zonas de fronteira entre Brasil (Corumbá) e Bolívia (Puerto Quijarro). De maneira a abarcar essa região específica, considerando a questão fronteiriça pertinente, em acordo com Canclini (1980), reconhecemos a necessidade de um olhar de sobrevoo para as manifestações artísticas latino-americanas, visando superar a tendência, estruturada em museus ao redor do mundo, em caracterizar a produção artística da América Latina, historicamente, quase que exclusivamente ao exotismo.

Tendo a discussão estética como um dos eixos que estruturam o trabalho que orientou esta investigação, é significativo indicar sob qual compreensão se desenvolve a construção deste discurso. Considerando a proposta envolvendo um conhecimento originado na América Latina e com a intenção de se reforçar os processos epistemológicos que o estruturam, compartilhamos da compreensão de Canclini (1980), para quem:

\footnotetext{
O Estético não é, então, nem uma essência de certos objetos, nem uma disposição estável do que se chamou "a natureza humana". É um modo de relação dos homens com os objetos, cujas características variam segundo as culturas, os modos de produção e as classes sociais. A definição do estético como o predomínio da forma sobre a função não é válida para todas as épocas, a não ser para a arte produzida no capitalismo como consequência da autonomia de certos objetos ou de certas qualidades de alguns objetos (CANCLINI, 1980, p. 11-12).
}

Ainda segundo o autor, pelo viés da estética o artístico se realiza na obra de arte e esta é autônoma, transcendendo representações históricas e diferenças culturais, e possibilitando o rompimento de fronteiras a partir da linguagem artística. Se tratando da condição estética atribuída à representação imagética museológica da América Latina, estrutura-se uma concepção que foi imposta a nações dependentes de países imperialistas, por meio de museus e afins, pois: "[...] a estética filosófica procurou universalizar sua reflexão, mas estava associada ao desenvolvimento da modernidade europeia, da razão ilustrada ou do romantismo" (CANCLINI, 2016, p. 37).

Isso se verifica quando aproximamos a compreensão dos trabalhos artísticos ao sistema de produção, que dita normas estabelecendo quais objetos têm relevância estética para ocupar espaços de divulgação, comércio, arquivamento de obras de arte. Porém, como também apresenta Morais (2003) encontra-se em curso transformações recentes nas discussões sobre a arte latino-americana quanto à tomada de consciência, por parte das vanguardas das artes plásticas, do esgotamento de suas experiências criadoras dentro de instituições fechadas e à experimentação de novas formas de inserção na cultura popular.

Esse outro modo de se colocar ao mundo, que implica nas relações de compreensão da arte, encontra sentido em contextos expandidos do pensamento que organiza as relações sociais que tem o ser humano como agente na contemporaneidade. Na perspectiva de Schwartz (2019), quando a autora reflete sobre as dinâmicas do lazer em meio virtual, contemplando também as manifestações artísticas articuladas pelo ser humano: "O prisma das mudanças impressas pelas eras digital e pós-digital é imenso e infindável, podendo ser ainda maior, dependendo do modo como se tem acesso às informações e dos arranjos sociais deflagrados pela necessidade de adaptação aos novos paradigmas” (p. 215). 
Historicamente, e indo ao encontro do processo que possibilita essa configuração, podemos recorrer a Benjamin (1987), para compreender o sistema de produção, no âmbito das artes visuais, lembrando, no entanto, que, segundo Bartra (2015), na contemporaneidade os artistas latino-americanos, fazem uso de sua regionalidade para tomada de consciência e como recurso da criação, especialmente aquelas situadas em um contexto popular (também identificado como naïf ${ }^{3}$ ) com foco social. Nesse contexto é oportuno destacar que a criação artística e os processos que envolvem sua compreensão passam pela percepção, que em acordo com Ostrower (2001):

[...] é a elaboração mental das sensações. A percepção delimita o que somos capazes de sentir e compreender, porquanto corresponde a uma ordenação seletiva dos estímulos e cria uma barreira entre o que percebemos e o que não percebemos. Articula o mundo que nos atinge, o mundo que chegamos a conhecer e dentro do qual nós nos conhecemos. Articula o nosso ser dentro do não-ser. Nessa ordenação dos dados sensíveis estruturam-se os níveis do consciente; ela permite que, ao apreender o mundo, o homem apreenda também o próprio ato de apreensão; permite que, apreendendo, o homem compreenda (OSTROWER, 2001, p. 12-13).

No âmbito da região fronteiriça de Puerto Quijarro e Corumbá, a cidade sul-matogrossense foi referência cultural, política e econômica da região centro-oeste até a chegada da ferrovia e a posterior divisão do estado de Mato Grosso ${ }^{4}$, quando a cidade de Campo Grande (capital no novo Mato Grosso do Sul) superou Corumbá comercialmente, afetando de modo significativo as demais relações de ambas as cidades (ITO, 2000).

$\mathrm{Na}$ contemporaneidade Corumbá é conhecida, em alusão à sua biodiversidade, como "capital do Pantanal" e grande parte das características históricas de sua existência são potencializadas politicamente através do Festival América do Sul Pantanal, evento anual que reúne música, dança, artes plásticas, artesanato, teatro entre outras manifestações populares, tanto da Bolívia quanto do Brasil, estendendo-se a outros países e culturas originárias da América Latina. Durante o $14^{\circ} \mathrm{FASP}^{5}$, realizado em 2018, a cidade de Corumbá contou com mais de 200 atrações durante os quatro dias do evento, entre elas uma mostra com pinturas de artistas de cidades da Bolívia e da cidade de Corumbá, reunidas em uma exposição intitulada "Conexão Santa Cruz", organizada pela Fundação da Cultura de Mato Grosso do Sul, em parceria com o SESC Corumbá e exibida neste local.

Assim, com o objetivo de identificar e compreender a materialidade e potenciais conceitos reunidos nas manifestações artísticas bidimensionais, com o objetivo de ampliar a percepção no campo que aborda a arte popular, neste estudo caracterizada na região fronteiriça entre a Bolívia e o Brasil, apresentamos a análise do trabalho de uma artista visual contemporânea residente na Bolívia e participante da exposição "Conexão Santa Cruz" durante o $14^{\circ}$ FASP.

\footnotetext{
3 “Naïf significa 'ingênuo' em francês, e o termo sugere uma associação com um suposto estado de pureza" (GOLDSTEIN, 2008, p. 305).

${ }^{4}$ O processo de divisão que originou o estado de Mato Grosso do Sul teve início em 1977 e foi concluído em 1979 (FERREIRA NETO, 2004).

${ }^{5}$ CORUMBÁ. FASP 2018 coloca Corumbá como protagonista da integração da América do Sul. 19 maio 2018. Disponível em: https://www.corumba.ms.gov.br/2018/05/fasp-2018-coloca-corumba-como-protagonistada-integracao-da-america-do-sul/. Acesso em: 20 maio 2020.
} 


\section{Procedimentos Metodológicos}

Metodologicamente $^{6}$, o desenvolvimento desta investigação se materializou por meio de uma pesquisa qualitativa (BOGDAN; BIKLEN, 1994), com ordenação integrada a partir de reuniões junto ao Núcleo de Investigação de Fenomenologia em Artes, e com encaminhamentos organizados em duas etapas: 1) pesquisa de descritores em plataformas online; 2) seleção, descrição, interpretação de obras bidimensionais criadas por uma artista da Bolívia, cujo trabalho nos atraiu durante a exposição "Conexão Santa Cruz". O uso desse procedimento se articula fenomenologicamente no sentido de que compreendemos a arte como:

[...] o pôr-em-obra da verdade, poiésis. Não somente o criar da obra é poietizante, mas também, do mesmo modo, o desvelar da obra é poietizante, apenas a seu próprio modo; pois uma obra somente é como uma obra real se nós próprios nos livramos de nossos hábitos e nos abrimos ao que se inaugura pela obra, para assim trazer nossa própria essência para o permanecer na verdade do sendo (HEIDEGGER, 2012, p. 191).

Durante a primeira etapa, utilizando os descritores "arte popular" e "estética latina", foi realizado um levantamento em plataformas online (CAPES; Biblioteca Digital Brasileira de Teses e Dissertações do Instituto Brasileiro de Informação em Ciência e Tecnologia; Google Acadêmico; SciELO.org; Oasisbr) objetivando encontrar produções acadêmicas com registros envolvendo a linguagem bidimensional nas artes visuais (desenho; gravura; pintura). Essa metodologia integra a continuidade de um conjunto de Pesquisas de Iniciação Científica originada em 2015, integradas ao Projeto de Pesquisa do orientador.

$\mathrm{O}$ recorte temporal sempre se estende para um ano antes da pesquisa que antecede a investigação em andamento, de modo a contemplar publicação com datas retroativas. No levantamento realizado, de 2016 a 2018, os descritores auxiliaram a encontrar três trabalhos: Gomes (2016), Silva e Santos (2016) e Mastroberti e Peres (2018).

Como é possível observar, o número de pesquisas envolvendo aspectos que apresentam fundamentos para se compreender as manifestações artísticas de origem popular na América Latina, desde uma perspectiva que demonstre a preocupação estética da representação dos trabalhos bidimensionais é ainda bastante restrito. Em acordo com Gomes (2016), que problematiza a diferença de valoração que recebem alguns "estilos" em face de outros, uma compreensão plausível para essa ausência de pesquisas tem fundamentos na origem dos artistas populares. Este pensamento é reforçado por Morais (2003), quando o autor diz que:

Falar da arte produzida por pessoas que não tiveram contato formal, clássico, acadêmico, ou seja lá como pode ser classificado o processo de formação consciente e voluntária, com a intenção de um aprendizado técnico para uma produção artística, com finalidades artísticas dentro de conceitos e metodologias ditas cultas ou eruditas, é falar em arte popular. Ainda que essa expressão sugira uma diferenciação, uma classificação, e sob alguns olhares até mesmo uma qualificação da arte, acredito que também carrega consigo uma identidade, algo vital para seu entendimento (MORAIS, 2003, p. 92).

Em sua dissertação, Gomes (2016) faz uma abordagem conceitual e histórica sobre a definição de arte popular, pautando-se por um viés sociológico a partir das relações do

\footnotetext{
${ }^{6}$ Originalmente a investigação que orientou o Trabalho de Iniciação Científica previa uma visita de campo à Bolívia para aproximação dos pesquisadores com o cenário cultural e social da cidade vizinha à Corumbá, no entanto, por conta de imprevistos e após análise que justificou a alteração do plano de trabalho, apresentada no relatório que antecede a finalização do PIBIC 2018/2019, essa fase da pesquisa foi descartada.
} 
popular com o erudito, com o mercado, com a criatividade, com o debate teórico e com o próprio contexto que envolve a sua produção. Para o autor, é imprescindível a ação dos museus, com pesquisas e ações educativas em prol da criação de uma rede que traga a cultura popular para dentro das relações cotidianas, que acaba migrando para o circuito urbano em prol de oportunidades de emancipação social, destacando ainda que:

Um olhar generalista, caricato, superficial e óbvio não alcança os pormenores, as subliminaridades e as nuances presentes nas expressões artísticas que emanam das camadas populares. Além disso, devemos refutar veementemente, combater, o já conhecido discurso elitista que confere à arte popular um espaço inferior no que se refere ao valor artístico de uma obra produzida pelos artistas populares e ainda desconsidera seus processos criativos, seus diálogos e questões, muitas vezes reduzindo-os a categoria de simples artesãos (GOMES, 2016, p. 49).

Nesse aspecto, Gomes (2016) destaca a relação entre campo e cidade por meio de um resgate da figura do Profeta Gentileza ${ }^{7}$, cuja ação estética envolve sua origem interiorana e a experiência com questões inerentes ao cotidiano urbano em que vivia. Segundo este autor:

Gentileza desenvolveu uma estética que hoje é facilmente reconhecível e amplamente copiada. Absorveu e transformou elementos completamente urbanos como pintura mural e grafitti, uso e desenvolvimento de fontes, e uso do espaço público como suporte para uma arte pública e política (GOMES, 2016, p. 57).

Em um contexto semelhante no que tange à compreensão do popular, Silva e Santos (2016) abordam o artesanato, enumerando diversas características que retomam as relações oriundas de movimentações sociais com a arte popular, principalmente a partir do conceito de lugar. Geograficamente situada em Quirinópolis-GO, a pesquisa de Silva e Santos (2016) se volta para a apresentação do espaço em que se comercializam esses trabalhos, que são geralmente confeccionados em unidades de produção familiar. Segundo Silva e Santos (2016), todos os fenômenos que regem as práticas populares artesanais caracterizam a formação e manutenção de identidades locais, valores familiares, entre outras características sociais, além de fomentar o turismo cultural - este último, do modo apontado por Morais (2003), em uma apropriação da criatividade popular:

[...] como base para recriações ou reelaborações eruditas tem sido uma constante da arte brasileira, desde muito tempo. E não se trata tão somente de temas [...] mas também de materiais e modos de produção [...]. Nos melhores artistas, essa transposição de determinadas técnicas e modos de produção específicos para o campo da criação erudita "impõe ao familiar uma substância poética que o torna subitamente estranho", ocasionando, no olhar do espectador, "um desequilíbrio, um descompasso das percepções e significações habituais” (MORAIS, 2003, p. 92).

É significativo destacar aqui que, como também pontua Morais (2003), foi a partir da Semana de Arte Moderna de 1922, o momento em que a arte popular começou a ganhar notoriedade e a ser estudada, como estofo de uma formulação da identidade artística brasileira proposta por Mario de Andrade.

\footnotetext{
${ }^{7}$ O Profeta Gentileza, cujo nome era José Datrino (1917-1996), foi um pregador urbano que circulou pelo Rio de Janeiro, de 1961 a meados de 1995, declamando e inscrevendo versos e mensagens de esperança. Sua presença foi inspiração para muitos artistas, com destaque à composição de Marisa Monte, que denuncia o apagamento de suas inscrições. Desde o ano 2000, o mural composto por suas inscrições em 56 pilastras do Viaduto do Gasômetro vem recebendo algum tipo de proteção e destaque, incluindo a criação de espaços de convivência, por parte do poder público carioca ou, mais recentemente, por organizações não governamentais (GUELMAN, 2014).
} 
Articulando esse contexto, o trabalho de Mastroberti e Peres (2018), traz o tema para a contemporaneidade - em uma abordagem diversa daquelas presentes nas outras produções levantadas - pela proposição da criação de um jogo digital que oferece suporte estético à exposição Aura Remastered, em conjunto com o Goeth Institut (Alemanha). O jogo funciona também como obra, com a produção de adesivos com elementos gráficos do jogo que podem ser aplicados em determinados pontos da exposição, fomentando o desenvolvimento de um espaço ludopoético, educativo e interativo junto às obras e aos artistas da exposição, uma vez que:

Esta era pós-digital deixa muito tênue a fronteira e interface entre as esferas biológica, física e digital. O delineamento de novos processos advindos da inclusão de inteligências e modelos diferenciados e diversificados de pensar introduzem novos benefícios, propiciando mais simplicidade (mesmo sob a complexidade de uma máquina), conveniência, preço e efetividade das ações. Porém, a percepção sobre bem-estar, felicidade, prazer e beleza está no olhar (e na sensibilidade) do humano (SCHWARTZ, 2019, p. 291).

Considerando esse delineamento e as percepções que se constituem nas relações humanas deste espaço, é simbólica a discussão de alguns conceitos que estruturam a ideia da exposição utilizada por Mastroberti e Peres (2018). Segundo eles a reprodução surge como um meio de facilitar o acesso à cultura e a disseminação da produção artística por meio da gravura e diferentes técnicas reprodutivas.

Mastroberti e Peres (2018) promovem uma crítica à aura da obra de $\operatorname{arte}^{8}$, que por meio das artes gráficas recebem uma possível democratização do acesso às produções culturais, otimizadas por meio de recursos digitais, estruturando um diálogo com o texto de Walter Benjamin: "A obra de arte na era da reprodutibilidade técnica", como aporte estético desta mediação. O jogo 9 se caracteriza como "obra aberta", diante das inúmeras possibilidades que podem ser criadas por quem o executa, trazendo a ampliação da técnica da gravura e a contextualização para com os trabalhos expostos e conceitos empregados, o que para seus autores, contribui para a crítica:

[...] o valor aurático da obra de arte e o modo como as artes gráficas, e o jogo digital como uma de suas categorias, se relacionam com um sistema que ainda se recusa a aceitar e à consagrar aqueles que se utilizam da cópia e reprodução como forma de democratizar a cultura artística, sobretudo os que se valem de recursos eletrônicodigitais como mídia e ferramenta (MASTROBERTI; PERES, 2018, p. 264).

Nessa proposição, a construção de um pensamento sobre a arte do povo seria possível se diversas áreas de conhecimento fossem utilizadas de modo sensível, objetivando a construção conjunta de vias de interpretação mais adequadas às manifestações populares. Nesse processo, atuaríamos como resistência ao discurso que desqualifica as manifestações populares, superando o discurso falacioso que estipula uma ordem de valores para movimentos ou estilos artísticos.

A segunda etapa dessa investigação se voltou para a análise de dois trabalhos de uma artista visual residente na Bolívia, Ejti Stih, com obras expostas na mostra "Conexão Santa Cruz”, organizada pela Fundação da Cultura de Mato Grosso do Sul, em parceria com o SESC Corumbá durante o Festival América do Sul Pantanal de 2018. Dentre o grupo de

\footnotetext{
${ }^{8}$ Em acordo com Walter Benjamim (2012), a aura da obra de arte encontra-se em sua autenticidade, originada e transmitida em face de sua materialidade e temporalidade histórica.

${ }^{9}$ No link a seguir é possível acessar o gameplay produzido: AURA REMASTERED - GAMEPLAY. 2018.1 vídeo (7 min 32 s.). Publicado pelo canal CALISQUÉDIO Artes Gráficas \& Sequenciais. Disponível em: https://www.youtube.com/watch?v=A97p_S-h2Ds. Acesso em: 15 abr. 2020.
} 
artistas residentes na Bolívia presentes na mostra, o trabalho da artista foi o único a compreender os quatro critérios selecionados na origem do Projeto de Pesquisa ao qual a investigação se encontrava relacionada:

a) competência inicial autodidata;

b) produção bidimensional;

c) representação de figuras humanas em seu trabalho;

c) temática envolvendo aspectos da vida cotidiana.

A escolha da artista Ejti Stih em detrimento a outros dois presentes na mostra "Conexão Santa Cruz", além da presença dos critérios apresentados, se deu por conta da relação que tivemos com seu trabalho na condição de fruidores/espectadores, reagindo a um convite da obra para a exploração de seus elementos compositivos, tanto pelo contato com os níveis representacionais das imagens quanto pelas possibilidades envolvendo os níveis simbólicos.

As produções analisadas, obtidas por registro fotográfico pessoal ou, via internet, foram interpretadas em seus níveis representacional (onde se identifica a imagem produzida a partir de referentes existenciais objetivos do artista ou do espaço em que se encontra situado) e simbólico (cuja expressão está associada especificamente à cultura original e à subjetividade manifesta de seu criador), em acordo com Dondis (2015) ${ }^{10}$.

A leitura das imagens ordenou-se por associações denotativas e conotativas, descrevendo a estrutura hermenêutica de seus significados, tendo por fundamentação as compreensões sobre a origem da obra de arte em face de sua concepção estética desenvolvidas por Heidegger (2012), na perspectiva de que para: "[...] achar a essência da arte, que vigora realmente na obra, procuraremos a obra real e perguntemos à obra o que ela é e como é" (HEIDEGGER, 2012, p. 41).

\section{RESULTADOS E DISCUSSÃo}

De acordo com Canclini $(1980 ; 2016)$, a arte participa do modo de produção em que está inserida e, nesse contexto, a obra pode sintetizar um complexo de relações sociais, transformações históricas e diferenças culturais, caracterizando uma linguagem sem fronteiras. Ainda segundo o autor, a estética compreende todos os momentos do processo artístico e ao defini-la, se estabelece um modo de relação dos homens para com os objetos.

Ejti Stih nascida no ano de 1957, na cidade de Kranj, Eslovênia (região que integrava a antiga Iugoslávia), onde cresceu e estudou até a graduação, vive e trabalha em Santa Cruz de la Sierra, na Bolívia, desde 1982. E é a partir de sua relação territorial e sensível com a Bolívia que Ejti Sthi declara sua identidade artística A cultura boliviana e seu ambiente geográfico estão sempre presentes em seus trabalhos, e as obras distorcem gêneros sociais, carregando mensagens políticas, pictoricamente expressionistas (Figura 1).

No trabalho de Ejti Stih observamos em primeiro plano, um conjunto de 5 homens. Dois desses homens seguram violões em postura de quem está tocando o instrumento. Um terceiro homem, no canto esquerdo do grupo, segura um livro em uma das mãos, enquanto com a outra apoia a têmpora esquerda. Há ainda dois outros homens neste conjunto, posicionados de forma a intercalar a tensão da linha que configura os demais.

Reunidos diante de uma superfície que associamos a uma mesa, onde se observam duas garrafas e cinco cálices com proporções variadas de uma bebida em tonalidade avermelhada, predomina a sugestão de um ambiente de confraternização. No segundo plano, à direita da imagem, a figura de um homem barbado, encontra-se recostada em um espaço iluminado da construção que ocupa o cenário da composição.

\footnotetext{
${ }^{10}$ Segundo Dondis (2015) existe ainda um terceiro nível: o abstrato, que em razão da especificidade desta pesquisa não foi considerado como instrumento para a análise.
} 
Figura 1: Sem título, 2017. Acrílica sobre tela, 150 x $90 \mathrm{~cm}$.

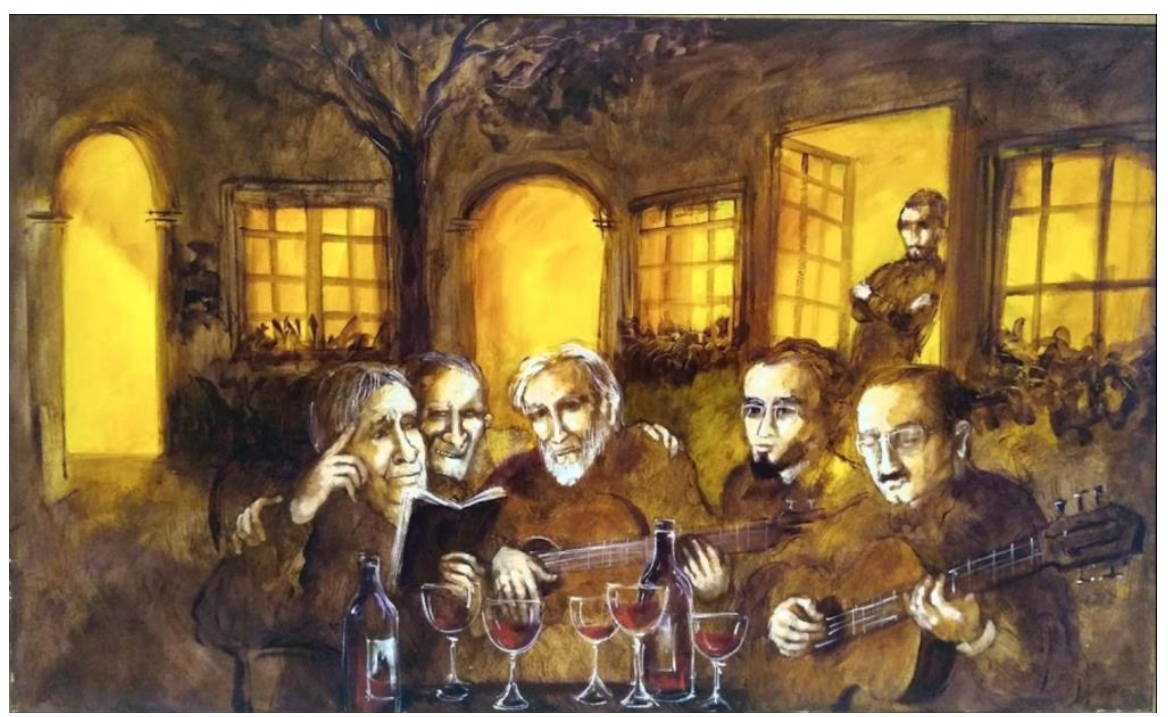

Fonte: Stih (2017)

No contexto da descrição que realizamos deste trabalho, é significativa a compreensão de Morais (1979), sobre a interpretação da obra, com quem compartilhamos. Segundo este autor:

Uma obra de arte verdadeira não se entrega nunca no primeiro olhar. [...] Muitas vezes, a compreensão da obra não se dá no momento mesmo do ato contemplativo. Mas em outro lugar ou momento. Quando se está vivendo uma experiência qualquer, no cotidiano, por mais banal de que seja. Como um flash, como se se completasse ali, naquele momento, o elo que faltava à compreensão (MORAIS, 1979, p. 162).

No contexto desse processo interpretativo, ao nos voltarmos para a obra, percebemos uma relação conotativa desse conjunto com um cenário de aproximação religioso. Nessa perspectiva, a paleta de cores que traz o amarelo em destaque, potencializa ainda mais a possibilidade de que o conjunto representacional teça uma relação simbólica com essa perspectiva.

Observando a construção que constitui o pano de fundo da imagem, encontramos a representação de três janelas, uma porta e dois arcos iluminados, a divisão entre o espaço interno e o ambiente externo se torna perceptível pelo contraste, além de situar a narrativa durante a noite, graças à ênfase da paleta de cores, em um recurso que cria sentido ao fluidor/espectador, considerando que "[...] os aspectos poéticos, aqueles que inauguram elementos e combinações entre os elementos, ampliando o campo do realizável, do perceptível e do comunicável, são manifestações [...] da capacidade de invenção e de transformação alcançada por um povo" (CANCLINI, 1980, p. 66).

É significativo destacar que apesar de ter seu trabalho organizado em uma mostra que foi identificada como "popular", exceto pela temática, nem a artista e nem os demais ali reunidos podem ser classificados nessa categoria. No caso específico de Stih, ao analisar a produção da artista, concordamos com Escobar (2008), quando o mesmo destaca o caráter temático do popular, que através de artistas experientes na vivência e representação desse tema, tornam a imagem desse contexto em espaço cultural e politicamente hegemônicos. $\mathrm{O}$ simbolismo da obra de Stih, se adequa a esta afirmação.

A segunda produção escolhida para a descrição neste trabalho foi obtida através de pesquisa online realizada para que fosse possível uma maior aproximação e abertura do 
repertório de imagens produzidas pela artista. Por meio de sua página pessoal na rede social Facebook, tivemos acesso a um acervo variado de seus trabalhos.

Deste conjunto de imagens, nos chamou a atenção o registro fotográfico de uma série denominada Migración, produzida no ano de 2016. Considerando a historicidade da artista e suas escolhas poéticas, nos pareceu coerente trazer a visualidade e descrição de uma das obras desta série para o presente trabalho, nesse contexto, selecionamos A la Orilla (Figura 2).

Figura 2: A la Orilla - série "Migración", 2016. Acrílica sobre tela, 130 x 160 cm.

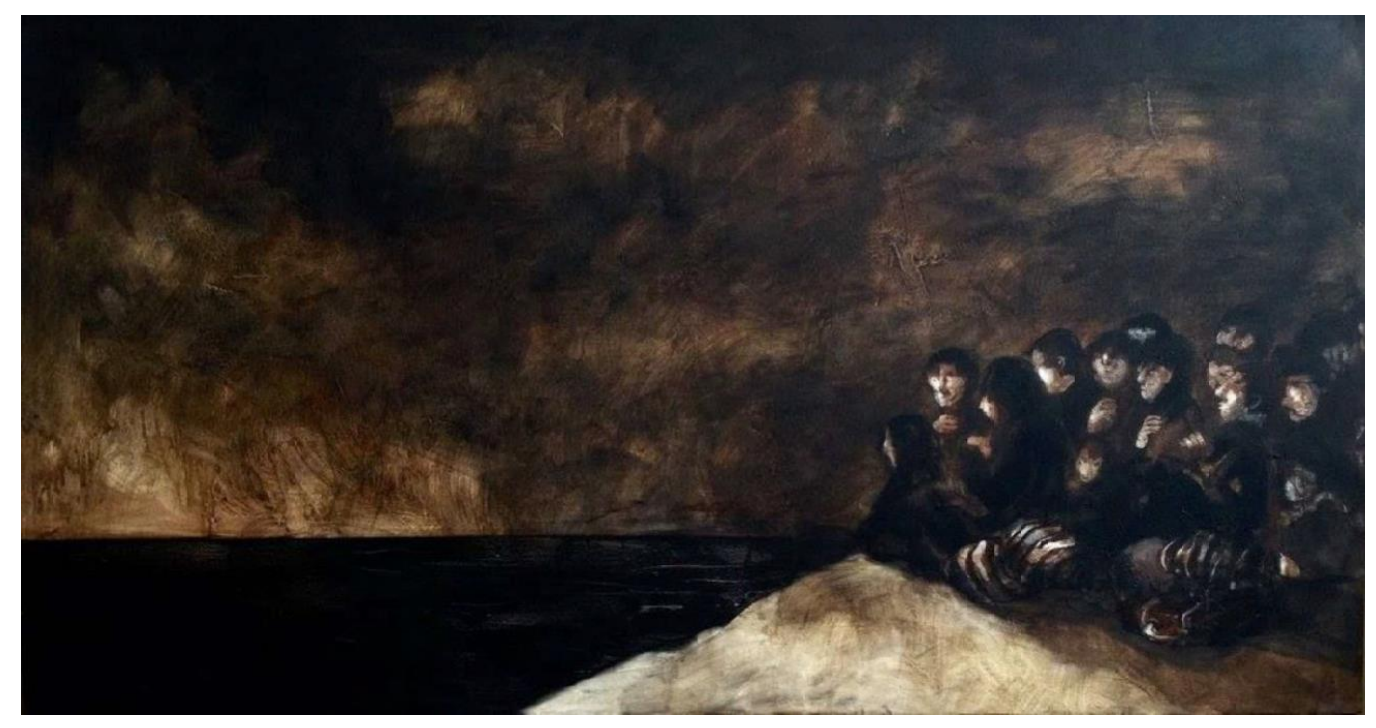

Fonte: Stih (2016).

A tela é composta de um grupo de pessoas reunidas em um conjunto denso ao lado direito, no primeiro plano da obra. No lado esquerdo da imagem percebemos uma estrutura que remete a uma porção de água, como se representasse um rio volumoso ou mesmo o braço de um mar. Ao fundo, sob uma aparente atmosfera nebulosa, percebem-se elementos que possibilitam visualizar tanto uma formação rochosa quanto uma floresta.

A pintura visível em primeiro plano, com formação triangular, denota um ponto de apoio/segurança para as figuras humanas que se encontram em seu entorno. Em sua simbologia, o triângulo, cujo histórico remete à divindade, ganha outra dimensão ao se encontrar deslocado para área inferior direita da obra, juntamente com as figuras humanas. A partir dos focos de luz que direcionam a leitura da obra, da esquerda para a direita (de forma cíclica), é possível perceber um direcionamento no olhar dos rostos que se insinuam nas figuras humanas, de enfrentamento com a região esquerda da obra, promovendo a sensação de medo/necessidade ao pensar em uma possibilidade de ultrapassar a região obscura. Em acordo com Canclini:

A objetividade da obra é, de acordo com Bernard Teyssedre, uma "objetividade por relação", isto é, mais ampla e mais estável que as variantes consideráveis. Quanto maior for a área com a qual se relaciona o objeto - sempre que a relação seja legítima e não uma apropriação reducionista como nas estéticas etnocêntricas - mais bem fundado e mais rico será o conhecimento e o juízo que se produzem. (CANCLINI, 1980, p. 79).

Assim como aponta Gomes (2016, p. 79): “O estudo da representação da cultura popular no imaginário passa necessariamente pelas questões de representação social e identidade", em concordância com as reflexões de Morais (2003; 1979) e Canclini (1980), 
observamos no trabalho de Ejti Stih todo um conjunto de significados simbólicos e representacionais cujas leituras nos permitem identificar a construção imagética de como o espaço circundante em que a artista vive estabelece afetos na compreensão que ela tem de si e do mundo em que vive. Considerando essas relações, percebemos a convergência entre os trabalhos produzidos dentro da esfera em que se situa o "popular" nas pesquisas, tanto nas produções que tem origem no próprio meio quanto naquelas que se materializam tendo esse campo como tema.

\section{CONSIDERAÇÕES}

Por meio das experiências proporcionadas pela pesquisa envolvendo a coleta de dados durante a FASP 2018, os estudos junto ao Núcleo de Investigação de Fenomenologia em Artes, o levantamento online de dados sobre as manifestações populares bidimensionais e o contato e estudos a partir dos trabalhos da artista selecionada para a reflexão desta investigação, foi possível identificar dois aspectos distintos sobre as interfaces da arte popular presente na região de fronteira Bolívia/Brasil, especificamente reunida na mostra "Conexão Santa Cruz" em Corumbá.

Em primeiro lugar, destacamos a prioridade do nível simbólico na materialidade dos trabalhos, compreendendo a relação humana com os objetos de sua cultura. O segundo aspecto aponta para a construção de uma ideia de arte popular, sustentada politicamente por demanda de uma intenção específica, muitas vezes criada, como aponta Benjamin (1987) para sustentar a existência do espaço que o trabalho (ou produto) artístico passa a ocupar.

Ambos os recortes se estendem de modo visualmente semelhante às demais produções reunidas naquela mostra, indicando o sentido ontológico do mundo que as e os artistas da região materializam em suas criações: o mundo vivido se manifesta na obra.

$\mathrm{Na}$ materialidade das manifestações artísticas bidimensionais, com abordagem popular de artistas que representam a Bolívia na FASP 2018, destacamos a autonomia de um discurso poético que, problematizando suas origens, desvela os interesses culturais e artísticos de um ideal apoiado na abordagem temática, fortalecendo os mitos de uma identidade situada. No campo investigativo, as materializações dessa produção continuam sendo, como observado, a verdade de uma compreensão de mundo sob o olhar daqueles e daquelas que o fazem visível.

\section{REFERÊNCIAS}

AURA REMASTERED - GAMEPLAY. 2018. 1 vídeo (7 min 32 s.). Publicado pelo canal CALISQUÉDIO Artes Gráficas \& Sequenciais. Disponível em: https://www.youtube.com/watch?v=A97p_S-h2Ds. Acesso em: 15 abr. 2020.

BARTRA, E. Arte popular y feminismo. Revista Estudos Feministas, v. 8, n. 1, p. 30-45, 2000.

BENJAMIN, W. A obra de arte na era de sua reprodutibilidade técnica. In: Duarte, R. (org.). O belo autônomo: textos clássicos de estética. Belo Horizonte: Autêntica, 2012. p. 277-314.

BENJAMIN, W. Arte e técnica, arte e política: ensaios sobre literatura e história da cultura. São Paulo: Brasiliense, 1987.

BOGDAN, R. C.; BIKLEN, S. K. Investigação qualitativa em educação: uma introdução à teoria e aos métodos. Porto: Porto Editora, 1994.

CANCLINI, N. G. A sociedade sem relato: antropologia e estética da iminência. São Paulo: EDUSP, 2016. 
Paulo César Antonini de Souza; Derick Trindade Bezerra

CANCLINI, N. G. A socialização da arte: teoria e prática na América Latina. São Paulo: Cultrix, 1980.

CORUMBÁ. FASP 2018 coloca Corumbá como protagonista da integração da América do Sul. 19 maio 2018. Disponível em: https://www.corumba.ms.gov.br/2018/05/fasp-2018-coloca-corumba-como-protagonistada-integracao-da-america-do-sul/. Acesso em: 20 maio 2020.

DONDIS, D. A. Sintaxe da linguagem visual. São Paulo: Martins Fontes, 2015,

ESCOBAR, T. El mito del arte y el mito del pueblo. Asunción, Paraguay: Centro de Artes Visuales/Museo del Barro, 2008.

FERREIRA NETO, J. Raízes de Coxim. Campo Grande: Editora UFMS, 2004.

GOLDSTEIN, I. Reflexões sobre a arte "primitiva": o caso do Musée Branly. Horizontes Antropológicos, v. 14, n. 29, p. 279-314, jan./jun. 2008.

GOMES, P. H. O. A arte popular entre o real e o fantástico: o imaginário na xilogravura e no cordel de J. Borges. 2016. 180 f. Dissertação (Mestrado em Artes) - Instituto de Ciências da Arte, Universidade Federal do Pará, Belém, 2016.

GUELMAN, L. O missionário saltimbanco. Revista de História da Biblioteca Nacional, v. 6, n. 63, p.28-30, dez. 2014.

HEIDEGGER, M. A origem da obra de arte. 6. ed. Petrópolis: Vozes, 2012.

ITO, C. A. Corumbá: o espaço da cidade através do tempo. Campo Grande: Editora UFMS, 2000.

MASTROBERTI, P.; PERES, C. Remasterização da aura da obra de arte em tempos de reprodutibilidade digital: projeto ludopoético a partir da exposição Aura Remastered. In: SBGAMES, 17., 2018, Foz do Iguaçu. Anais [...]. Foz do Iguaçu, 2018. p. 263-269.

MORAIS, F. O Brasil na visão do artista: o país e sua cultura. São Paulo: Sudameris, 2003.

MORAIS, F. Artes plásticas na América Latina: do transe ao transitório. Rio de Janeiro: Civilização Brasileira S.A., 1979.

OSTROWER, F. Criatividade e processos de criação. Petrópolis: Vozes, 2001.

SCHWARTZ, G. M. Motricidade (pós)humana e a abordagem sobre o corpo na era da simulação. Motricidades: Revista da SPQMH, v. 3, n. 3, p. 213-221, set.-dez. 2019.

SILVA, M. C.; SANTOS, J. C. V. Artesanato, arte e cultura local: uma possibilidade de renda e desenvolvimento da atividade turística. Caminhos da Geografia, v. 17, n. 60, p. 31-47, 2016.

STIH, E. Sem título. 2017. 1 original de arte, acrílica sobre tela, 150 x $90 \mathrm{~cm}$. Coleção particular.

STIH, E. [A la Orilla]. [2016]. 1 gravura. Disponível em: https://www.facebook.com/ejtistih/photos/1177612128950796. Acesso em: 20 maio 2020.

Recebido em: 30 nov. 2020. Aprovado em: 17 dez. 2020. 